keeper of botany at the British Museum (Natural History) was elected president of the Union for 1942-43; in recent years he has served the Union as president of the Botanical Section. The new treasurer is Sir Gordon Hearn.

"Fungi and the Biology of Man" was the title of Dr. Ramsbottom's presidential address. He stated the facts concerning struggle and survival in fungi, the existence of races and their immutability, parasitism and symbiosis in outline: points of similarity and of contrast in man were indicated. Man does not inherit acquired characters in a biological sense, but he is heir to every other change. No pure races of man exist and the theory of race and blood is nonsense. Competition or struggle is universal, but in symbiosis an equilibrium has been attained. Competition in modern man is, for the most part, sociological and not biological. The State is an organization and not an organism. War between States is not a biological necessity nor is it transcendental. Man has his full complement of biological characters at birth : they are immutable. His ideas, his theories, his wishes are developed through culture : they can be changed and therein lie the hopes of civilization.

At the sectional sessions the following papers were read: "Historic London under Fire", by E. Yates, who exhibited the deplorable damage to medieval buildings caused by enemy action; "Studies in the Variation of Native Plants", by Dr. A. R. Clapham, who advocated co-operation by botanical societies for the proposed new Biological Flora of the British Isles (J. Brit. Ecol. Soc., 356; 1941) ; "Constructional Elements in the Physiography of the Southern Counties of England", by F. Owen Whitaker; "Spiders and their Life History and Habits", by E. A. Robins, who described a spider new to the British list, Marinda aurantia, the golden garden spider of America.

In the afternoon, Dr. W. St. Lawrence Finny, the retiring president, conducted a perambulation visiting and describing the history of St. Mary's Church, Guildford Castle and Museum, the Guildhall and its regalia and the Abbot's Hospital of 1619. Botanists visited the Compton district; geologists the Guildford brickworks and the Lower Greensand beds at Compton. It had been suggested that this Congress should be at Haslemere but, this being impracticable, the zoologists went there by train to see exhibits arranged in the Haslemere Educational Museum. There was a special exhibit of native flowers arranged by the Guildford Natural History Society, the officers of which organized local arrangements, and it was pleasing to see flowering specimens of our ancient woad, Isatis tinctoria L., now classed in most Floras as "a casual alien".

T. DANNREUTHER.

\section{THE ONTARIO RESEARCH FOUNDATION*}

\footnotetext{
THE report of the Ontario Research Foundation for the year 1941 includes the report of the Director, the audited financial statement and a list of publications issued to December 31, 1941. During the year the work of the Foundation has been increasingly concerned with problems associated directly

* Ontario Research Foundation. Report for the Year 1941. Pp. 25. (Ottawa, 1942.)
}

or indirectly with the War, and owing to the nature of much of the work in this field, as well as on problems of civilian production arising out of war-time restrictions on supplies of all kinds, a detailed reference to much of the work is not possible. The creation of centralized inspection laboratories has relieved the staff of much of the work in organizing and conducting laboratory work on behalf of the InspectorGeneral, but the securing and training for effective service of young graduates and technicians is a serious problem, although problems associated with personnel have been considerably reduced by the help of the local Registrar for Military Service. The quick and effective results which follow from full co-operation between men with long experience in industry and a scientific group actively engaged in research on the processes and materials of the industry have been demonstrated, and although it is clear that relations with industry require further development, the Director suggests that problems of the post-war period will afford a further opportunity for economical and effective work along these lines.

In the Department of Biochemistry, the Leather Laboratory has been used to varying extents by the Department of National Defence and the InspectorGeneral, and work on Service specifications has been continued in collaboration with the National Research Council. Preliminary tests have been made of a modified abrasion-testing machine for leather, and the production of organic acids from sugar by chemical and microbiological methods has continued. Methods for crude and refined lactic acid are now in use on a commercial scale in Toronto. A good deal of time has been devoted to a careful comparison of chemical and microbiological methods for determining the vitamin $B_{1}$ content of foodstuffs, including bread. In the Department of Agriculture, the Pathological Laboratory has investigated the infection of small experimental animals with Ascaris lumbricoides, and the same Department has now completed the greater part of its field work on the climate and main soil types of southern Ontario, and in co-operation with the Federal Department of Entomology has made a rapid survey of southern Ontario to determine the location and extent of nematode infection in oats.

In the Textile Department a reasonable balance has been maintained between testing, short-term problems and more fundamental research, and an investigation has been undertaken on the treatment of various synthetic fibres to overcome the serious drawback that they cannot be given a high degree of twist in their natural state without serious troubles developing in the knitting operation, and encouraging results have been obtained in collaboration with the Dominion Silk Mills, Ltd. Partly successful attempts have been made to obtain new products for processing wools from raw materials which are and will be available in Canada.

In the Department of Chemistry, the organic and metallurgical analytical laboratories have continued to operate on behalf of the Inspector-General and there has been a marked increase in the number of problems submitted by outside firms. The Gas Laboratory has given several months to the study of steaming of horizontal retorts at one of the plants of the Consumers' Gas Company, and in the Department of Metallurgy gauge-testing, heat-treatment, physical testing and metallography services have been available to Government departments and manufacturers, and the long-term research programme has largely been brought to a standstill. 